\title{
Effects of sodium lignosulfonate on bismuth electrochemical deposition on copper surfaces from $\mathrm{HCl}-\mathrm{NaCl}-\mathrm{BiCl}_{3}$ solution
}

\author{
Yun-long $H E^{1}$, Rui-dong XU ${ }^{1,2, *}$, Shi-wei $H E^{1}$, Han-sen $C H E N^{1}, K u o L^{1}$, Yun ZHU ${ }^{1}$, Qing-feng SHEN ${ }^{1}$ \\ ${ }^{1}$ Faculty of Metallurgical and Energy Engineering, Kunming University of Science and Technology, \\ Kunming 650093, China; \\ ${ }^{2}$ State Key Laboratory of Complex Nonferrous Metal Resources Clean Utilization, Kunming 650093, \\ China \\ *E-mail: rdxupaper@aliyun.com
}

doi: $10.20964 / 2018.08 .52$

Received: 23 April 2018 / Accepted: 31 May 2018 / Published: 5 July 2018

\begin{abstract}
The effects of sodium lignosulfonate (SLS) on bismuth electrochemical deposition on copper surfaces from $\mathrm{HCl}-\mathrm{NaCl}-\mathrm{BiCl}_{3}$ solution were investigated. Cyclic voltammetry studies indicated that $\mathrm{Be}^{3+}$ ions could be reduced electrolytically to bismuth on the surface of copper in the presence of different concentrations of SLS and that $0.3 \mathrm{~g} / \mathrm{L}$ of SLS was beneficial for the electroreduction of $\mathrm{Bi}^{3+}$. The cathodic polarization study indicated that SLS had a noticeable effect on the Tafel slope and exchange current density but no significant effect on the transfer coefficients. SEM images revealed that the deposit grain size decrease remarkably when sodium lignosulfonate was added to the electrolytic bath and that the main textures of the deposits changed from a blocky structure to a lamellar structure when the sodium lignosulfonate concentration increased from 0.1 to $0.4 \mathrm{~g} / \mathrm{L}$. XRD analysis indicated that the addition of sodium lignosulfonate could slightly suppress the (110) orientation and enhance the other crystallographic orientations significantly and that the most significantly enhanced crystallographic orientation was the (104) plane.
\end{abstract}

Keywords: sodium lignosulfonate, bismuth, deposit morphology, crystallographic orientation

\section{FULL TEXT}

(C) 2018 The Authors. Published by ESG (www.electrochemsci.org). This article is an open access article distributed under the terms and conditions of the Creative Commons Attribution license (http://creativecommons.org/licenses/by/4.0/). 